\title{
Communication \\ Porous Carbon Monoliths Made from Cellulose and Starch
}

\author{
Olaf Klepel ${ }^{1, *}$ and Nina Danneberg ${ }^{2}$ \\ 1 Institute of Materials Chemistry, Brandenburg University of Technology Cottbus-Senftenberg, \\ Universitätsplatz 1, D-01968 Senftenberg, Germany \\ 2 Faculty of Mechanical Engineering, Electrical and Energy Systems, Brandenburg University of Technology \\ Cottbus-Senftenberg, Universitätsplatz 1, D-01968 Senftenberg, Germany; nina.danneberg@b-tu.de \\ * Correspondence: olaf.klepel@b-tu.de; Tel.: +49-3573-85-864
}

Received: 22 April 2020; Accepted: 16 May 2020; Published: 19 May 2020

check for updates

\begin{abstract}
Porous carbon monoliths can be used as key components in a variety of applications, such as energy storage, adsorption and catalysis. The preparation of porous carbon monoliths suffers from several limitations, e.g., time-consuming synthesis steps, the use of hazardous chemicals, limited porosity or mechanical stability. This paper describes the investigation of a simple synthesis route to produce porous carbon monoliths from sustainable carbon precursors. Mixtures from different kinds of cellulose and starch, respectively, have been used as the carbon precursor. Fundamental features of porous monoliths, i.e., the porosity and the mechanic stability, respectively, have been investigated in dependence on the composition of the precursor mixtures. First attempts to explain the observed behavior have already been made.
\end{abstract}

Keywords: porous carbon monoliths; cellulose; starch; fracture strength

\section{In troduction}

Biomass has been used as basic resource for food, energy and material, respectively, from the beginning of mankind. With the beginning of the industrial revolution, biomass as the energy source has been partly replaced by fossil resources. Furthermore, the availability of coal and mineral oil initiated the development of a new industrial branch — the chemical industry-in the last two centuries. However, with the anthropogenic climate change and the fossil fuel depletion, the re-introduction of biomass into the value-added chain has become one of the core challenges of our time. Therefore, biorefineries, in which biomass is converted to energy products, have taken up a key position [1]. In particular, lignocellulosic refineries are considered as the most promising because they do not compete with the production of food from biomass. In these biorefineries, lignocellulosic biomass is pulped into its basic components cellulose, hemicellulose and lignin, respectively. A part of these compounds is converted into ethanol as the main compound of bio-fuel. However, the economic sustainability of lignocellulosic biorefineries can be significantly improved by the co-production of value-added chemical by-products. In this context, lignin is for example discussed as a promising raw material for bioplastics. Cellulose, on the other hand, is a polysaccharide which can be used in many ways. It can be converted into sugars from which important basic chemicals (e.g., ethanol, lactic acid, succinic acid) can be produced [1]. Besides this, it can also be used as a component of materials or as a precursor for material synthesis. So, the production of viscose and its follow-up products (e.g., cellophane, art silk) has been known for more than one century. Nowadays, novel applications of cellulose derivates such as the processing of cellulose acetate as a thermoplastic material by fused filament fabrication have been reported [2]. Besides cellulose, starch is another polysaccharide which has become increasingly important as a raw material for bio-plastics or other functional materials [1]. 
One of the most important materials which can be produced from polysaccharides is porous carbon. Porous carbons are widely used in a variety of applications such as catalysis, filtration and sensor technology. In the context of energy transformation, novel applications for energy conversion or storage are increasingly attracting attention. Therefore, many efforts have been made to improve the performance of electrochemical systems, e.g., batteries, fuel cells and supercapacitors, respectively. Here, porous carbon materials play a key role as electrodes due to their chemical inertness, high surface area and conductivity [3-6]. These features are also beneficial for their use in heterogeneous catalysis.

Porous carbons can be obtained in various ways. The classical way is the so-called activation of carbons and carbon precursors by activating agents like steam, $\mathrm{CO}_{2}, \mathrm{ZnCl}_{2}, \mathrm{H}_{3} \mathrm{PO}_{4}$ or $\mathrm{KOH}[4,7]$. In addition to the activation method, other methods based on phase separation processes or using templates have been extensively investigated [6,8-11]. Furthermore, in some cases the intrinsic porosity of carbon precursors has been transferred to the carbon material by controlled carbonization [12,13]. However, the porosity of these materials is rather low in comparison with that of classically activated carbons.

There is a large variety of carbon precursors to produce porous carbons. Classical activated carbons are mostly made from forest, industrial or agricultural waste products [4]. However, the use of such materials for novel applications (e.g., electrochemistry) is limited due to their non-defined composition. For this reason, numerous attempts have been described over the last two decades to produce porous carbons from pure substances obtained from renewable raw materials. Among these carbon precursors, polysaccharides play a prominent role [13-15]. The challenge to prepare carbons with defined properties from polysaccharides is due to the fact that different polysaccharides can significantly differ in their molecule structure and morphology. On the molecular level, starch consists of two different molecules: the branched amylopectin and the linear - helical amylose. The macroscopic nature is built up by water-insoluble granules, which contain semi-crystalline ordered regions [16]. Cellulose, on the other hand, is a non-branched macromolecule which consists of several hundred to many thousands of linked D-glucose-units. It shows a rather stiff, rod-like conformation whereas hydrogen bonds between neighbored chains cause the formation of microfibrils with high tensile strength. Cellulose is much more crystalline than starch [17]. The question is, in what way are these differences of the precursor's features reproduced in the features of the corresponding carbons?

For many technical applications, porous monoliths are preferred to powders, as the latter can cause a pressure drop in flow apparatus. Furthermore, particles from powders could accidentally get in the apparatus, causing technical damage. So far, numerous strategies to prepare porous carbon monoliths have been developed. For optimal mass transport, the porous monoliths should possess hierarchical arranged pores with different pore widths. As the so-called macropores (diameter larger $50 \mathrm{~nm}$ according IUPAC recommendation) are the pores for rapid mass transport, the micropores (diameter smaller $2 \mathrm{~nm}$ ) provide the large surface area. Monoliths can be produced from powders using binders. However, these binders are rather non-porous and so the monoliths lose part of their porosity. Alternative methods are based on the use of hard or soft templates. These synthesis routes, however, often include time-consuming steps and, in case of hard templates, require hazardous chemicals such as hydrofluoric acid [18-24].

The aim of this communication consists in basic investigations of the preparation of porous carbon monoliths from polysaccharides with different structural and morphological features. These investigations should lay the foundation for novel modular preparation concepts. Two aspects are the focus of our interest:

1. The development of a template-free and easy route to prepare porous carbon monoliths.

2. The identification of relations between the structural and morphological features of the different carbon precursors and the mechanical and textural features of their corresponding carbon materials.

For that, four different types of cellulose and starch, respectively, were used as the carbon precursors, namely microcrystalline cellulose, cellulose fibers, potato starch and wheat starch. Although very similar in their elemental composition, these compounds differ considerably in their molecular structure and morphology. 


\section{Materials and Methods}

\subsection{Materials}

Different mixtures consisting of different types of cellulose and starch, respectively, were used as the carbon precursor. Microcrystalline cellulose (Alfa Aesar by Thermo Fisher Kandel GmbH, Kandel, Germany) and cellulose fibers (Carl Roth GmbH \& Co. KG, Karlsruhe, Germany) were used as the cellulose species. The starch originated form wheat (Carl Roth GmbH \& Co. KG, Karlsruhe, Germany) and potato (VWR In ternational GmbH, Darmstadt, Germany); further details are given in the Supplementary Materials section (Table S1). X-ray diffraction patterns and microscopic images of the precursors are shown in the Supplementary Materials section (Figures S1, S2, S3 and S4, respectively). Four series of samples varying in their precursor composition were prepared (Table 1).

Table 1. Composition of the used carbon precursor mixtures.

\begin{tabular}{llll}
\hline Carbon Precursor 1 & Carbon Precursor 2 & Starch Content (wt.\%) & Sample Denotation \\
\hline cellulose fibers & wheat starch & $10 \ldots 50$ & $\mathrm{FWx}$ \\
cellulose fibers & potato starch & $10 \ldots 50$ & $\mathrm{FPx}$ \\
microcrystalline cellulose & wheat starch & $10 \ldots 50$ & $\mathrm{MWx}$ \\
microcrystalline cellulose & potato starch & $10 \ldots 50$ & $\mathrm{MPx}$ \\
\hline
\end{tabular}

* The extended version of Table 1 is shown in the Supplementary Materials section (Table S2).

A copper sleeve (26 mm diameter, $38 \mathrm{~mm}$ length) was used as the mold. The mold was filled with an aqueous suspension of the carbon precursor (mass ratio precursor/water 0.43). Subsequently, part of the water was removed by slight pressing with a punch. The filled sleeve was then dried in an oven at $323 \mathrm{~K}$ overnight and further dried at $373 \mathrm{~K}$ until mass constancy was reached. The dried precursor mixture was carbonized in a tube furnace $(873 \mathrm{~K}, 3 \mathrm{~h}$, nitrogen flow). A scheme of the preparation process is shown in the Supplementary Materials section (Figure S5).

For activation, aqueous solutions of potassium hydroxide ( 3 molar, 9 molar; Merck KgaA, Darmstadt, Germany) were freshly prepared. The carbon monoliths were infiltrated with the potassium hydroxide solution under vacuum $(4 \mathrm{KPa})$ in a desiccator. This process was repeated several times until the monolith had sunk to the bottom of the desiccator under normal pressure. The infiltrated monoliths were then dried at $383 \mathrm{~K}$ in an oven overnight. The monoliths were then thermally treated by a two-step sequence to perform the activation process (tube furnace, nitrogen flow, 573 and $1073 \mathrm{~K}$, respectively). After cooling, the monoliths were thoroughly washed with water until the $\mathrm{pH}$-value of the water reached about seven.

The samples are denoted as follows: FW10_3 stands for carbon made from cellulose fibers and wheat starch (content 10 wt. \%), activated with 3-molar KOH solution. On the other hand, MP30_9 means carbon made from microcrystalline cellulose and potato starch (content $30 \mathrm{wt}$. \%), activated with 9-molar $\mathrm{KOH}$ solution.

\subsection{Characterization Methods}

Nitrogen adsorption and desorption isotherms were measured at $77 \mathrm{~K}$ on a Micromeritics ASAP 2020 (Micromeritics GmbH, Unterschleißheim, Germany) volumetric adsorption system. The specific surface area $S_{\mathrm{BET}}$ and the total pore volume $V_{\mathrm{sp}}$ were determined using the BET equation and the single point method, respectively.

To observe the morphology features of the carbons, images were taken using a Philips XL30 scanning electron microscopy (SEM, FEI Company, Eindhoven, The Netherlands). Imaging was carried out at $30 \mathrm{kV}$ accelerating voltage.

The total porosity is defined as the ratio of the total pore volume to geometric volume of the monolith. First, the difference between the geometric volume and the carbon skeleton volume of the monoliths was calculated. For that, the skeleton volume was measured by helium pycnometry on 
a Porotec Pycnomatic ATC (Porotec GmbH, Hofheim/Ts., Germany) equipment. That difference was then divided by the geometric volume of the monolith. As a consequence, the values can vary between zero and one.

The fracture strength was investigated by measuring the force-deflection with an INSPECT 10 Table Blue universal testing machine (Hegewald and Peschke $\mathrm{GmbH}$, Nossen, Germany). The specimens were placed between two parallel plates and then stretched to break. The breaking strength was calculated from the measured force and the area of the sample under investigation. Five different samples of each material were examined for reproducibility. For discussion, the fracture strength, the average of the values thus obtained, was calculated.

\section{Results and Discussion}

\subsection{Macroscopic Features and Morphology of Carbon Monoliths}

The preparation of stable carbon monoliths by carbonization of pure starch was not successful because the material obtained was rather powdery. In contrast, the carbon monoliths obtained from cellulose have a defined geometric, cylinder-like shape. Due to the shrinking during the drying and the carbonization process, all monoliths are smaller than the size of the mold. However, the shrinking does not proceed equally for each material because the size of the monoliths depends on the composition of the precursor mixture. In general, fiber-derived monoliths are larger than monoliths from microcrystalline cellulose (Figure S6, Supplementary Material section). Among the microcrystalline derived carbons, those with high starch content are considerably larger than the others (Table 2).

Table 2. Geometrical size of carbon monoliths obtained from different precursor compositions.

\begin{tabular}{ccccc}
\hline Series & $\begin{array}{c}\text { FWx; FPx } \\
\text { (Low Starch } \\
\text { Concentration) }\end{array}$ & $\begin{array}{c}\text { MWx; MPx } \\
\text { (Low Starch } \\
\text { Concentration) }\end{array}$ & $\begin{array}{c}\text { FWx; FPx } \\
\text { (High Starch } \\
\text { Concentration) }\end{array}$ & $\begin{array}{c}\text { MWx; MPx } \\
\text { (High Starch } \\
\text { Concentration) }\end{array}$ \\
\hline length $(\mathrm{mm})$ & $14.5 \ldots 17.0$ & $12.5 \ldots 15$ & $14.5 \ldots 17.0$ & $17.5 \ldots 20.0$ \\
diameter $(\mathrm{mm})$ & $17.0 \ldots 18.5$ & $12.5 \ldots 13.5$ & $17.0 \ldots 18.5$ & $17.5 \ldots 20$ \\
\hline
\end{tabular}

The reason for this must be assumed to be the swelling of the starch [16]. Starch swells in the presence of water at slightly increased temperature. Such conditions are almost fulfilled at the beginning of the carbonization procedure, which involves_among other things—an increase of temperature and the release of water. The swelling could contribute to the enlargement of the monoliths, especially at higher starch content.

The morphology of the carbons investigated by SEM is strongly dependent on the nature of the carbon precursor (Figure 1). As starch derived carbons have a known foamy morphology [15], the carbons from cellulose are structured more compactly. Among the latter mentioned, the carbons obtained from microcrystalline cellulose show a morphology consisting of small units, but they are more compact than those from cellulose fibers. In these carbons, the fiber morphology could partly be preserved.

The carbons obtained from mixtures of microcrystalline cellulose and starch show images in which elements of the individual compounds (cellulose- and starch-derived carbons, respectively) are connected with each other (Figure 1, Figure 2, Figure 3). This is especially visible in the materials prepared from starch-rich mixtures. Here, the small elements of microcrystalline-derived carbons are still visible, but they are arranged in a more foam-like morphology which stems rather from the starch-compound. 

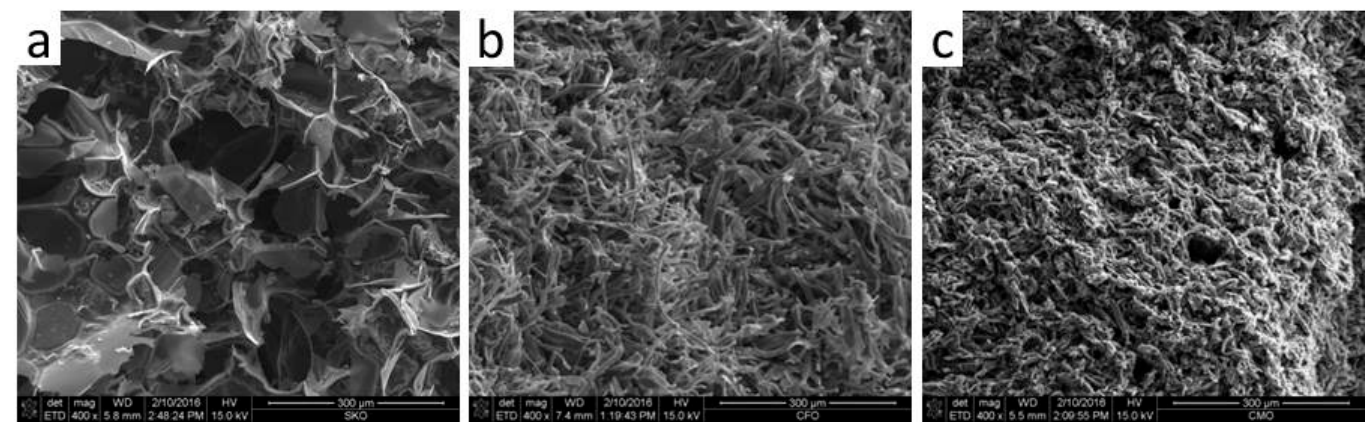

Figure 1. SEM images of the carbonized precursors starch (a), cellulose fibers (b), microcrystalline cellulose (c).
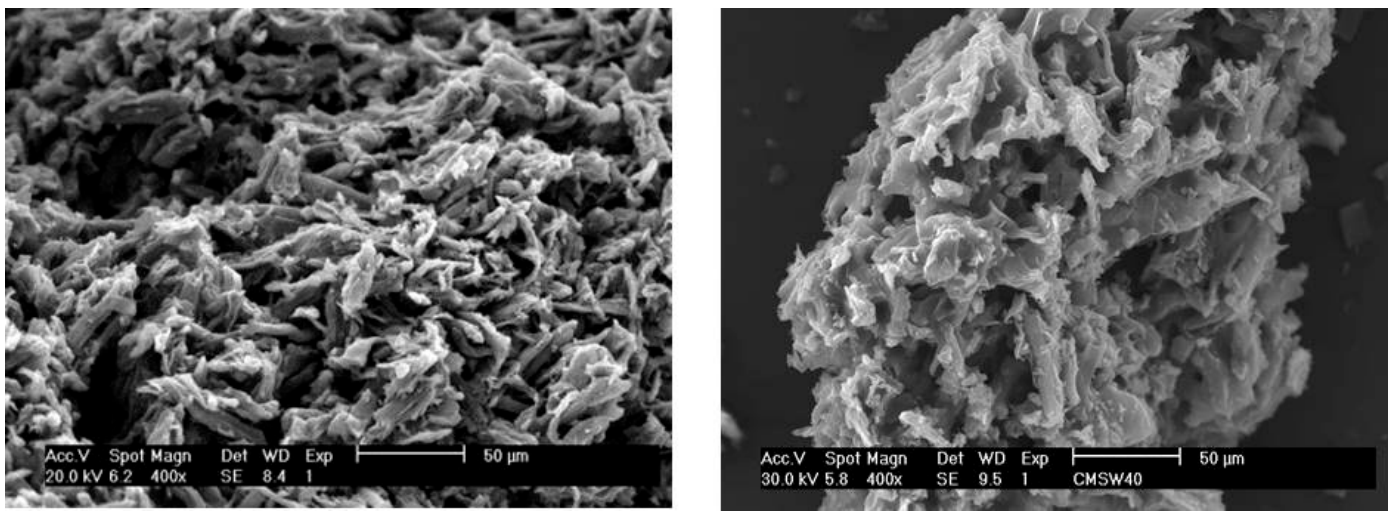

Figure 2. SEM images of carbons from microcrystalline cellulose and different amounts of wheat starch: $10 \mathrm{wt}$ \% (left hand side) and $40 \mathrm{wt}$. \% (right hand side).
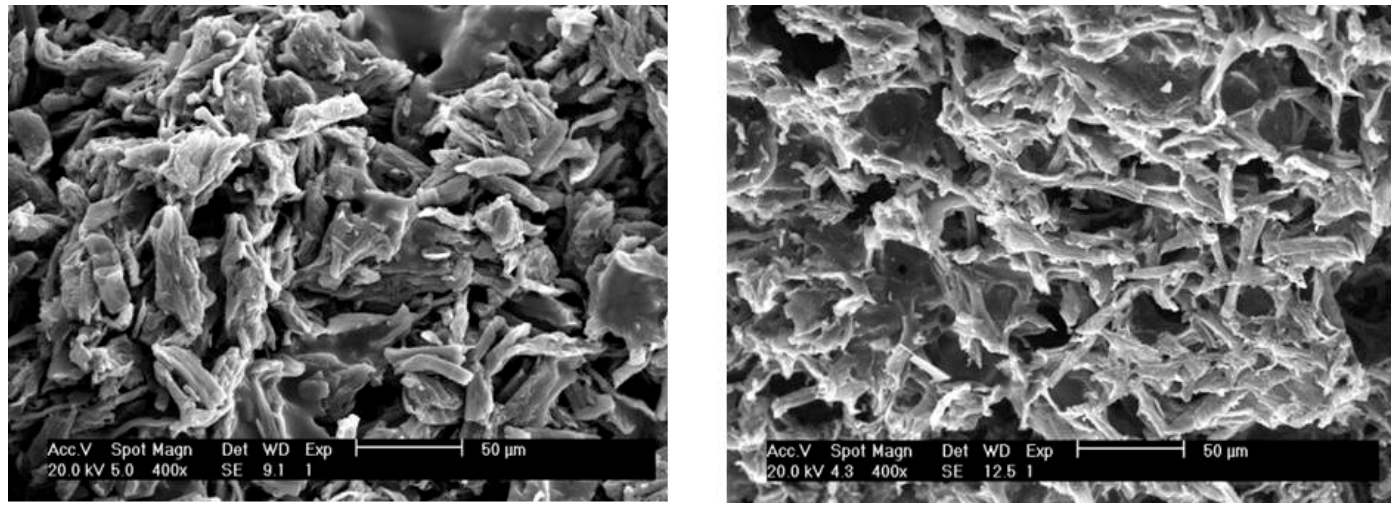

Figure 3. SEM images of carbons from microcrystalline cellulose and different amounts potato starch: 10 wt. \% (left hand side) and 50 wt. \% (right hand side).

\subsection{Porosity}

The dependence of the total porosity on the nature and composition of the carbon precursor, respectively, is shown in Figure 4. 


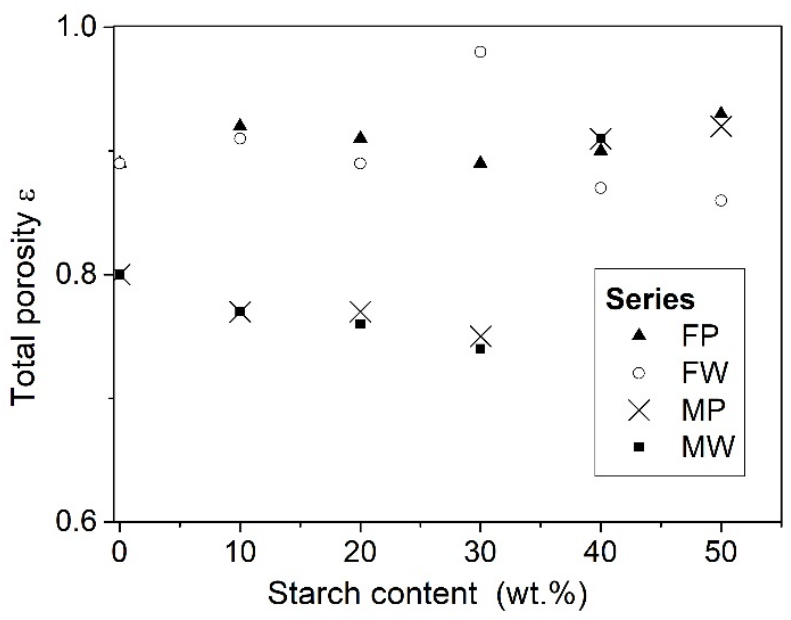

Figure 4. Dependence of the total porosity on the nature and composition of the carbon precursor.

In general, the total porosity of carbon derived from fibers is somewhat higher than that of carbon derived from microcrystalline cellulose. Among the latter mentioned materials, there is a slight but not steady dependence of the porosity from the starch content of the synthesis mixture. At lower starch content, the porosity decreases slightly with increasing starch content. However, at the higher starch content of 40 and $50 \mathrm{wt}$. \%, respectively, the porosity jumps from about 0.75 up to about 0.9 . Note, these monoliths prepared with higher amounts of starch have not only higher porosity but also higher geometric volume, i.e., larger length and diameter, respectively. As mentioned above, the swelling of starch has been assumed as the reason for the increase in geometric size. Obviously, that process is controlled by the formation of macropores which contribute to the larger total porosity.

The total porosity of the activated materials is in most of the cases somewhat larger than that of the non-activated starting materials. On carbons prepared with a high amount of starch (40 and $50 \mathrm{wt}$. \%, respectively), the activation did not cause any increase of total porosity.

To investigate the micro- and mesoporosity, nitrogen adsorption isotherms have been measured. Isotherms of carbons made from microcrystalline cellulose are shown in Figure 5.

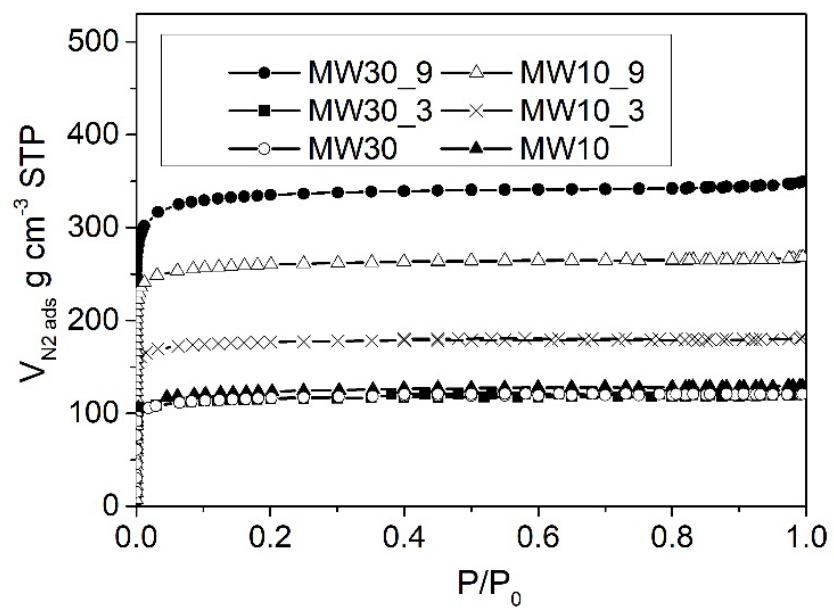

Figure 5. Nitrogen adsorption isotherms of selected carbon materials made from microcrystalline cellulose.

For clarity, only five representative samples are shown. The other materials follow nearly the same trend and their textural data are given in the Supplementary Materials section (Tables S3-S8). All isotherms correspond to type I-isotherms according the IUPAC recommendation [25]. So, the pores which could be detected by this method are sole micropores. Note, macropores, i.e., pores with diameters larger than $50 \mathrm{~nm}$ cannot be detected by nitrogen adsorption measurement. The differences 
in the adsorbed nitrogen amount of the non-activated samples are rather low and mostly within the range of the experimental error, indicating that all materials are apparently similar in their micropore system (Table 3 and Supplementary Materials).

Table 3. Textural data of samples shown in Figure 5.

\begin{tabular}{lllllll}
\hline & MW10 & MW10_3 & MW10_9 & MW30 & MW30_3 & MW30_9 \\
\hline$V_{\text {sp }}\left(\mathrm{cm}^{3} \mathrm{~g}^{-1}\right)$ & 0.20 & 0.28 & 0.42 & 0.19 & 0.18 & 0.53 \\
$S_{\mathrm{BET}}\left(\mathrm{m}^{2} \mathrm{~g}^{-1}\right)$ & 415 & 591 & 870 & 391 & 387 & 1122 \\
\hline
\end{tabular}

Activation with low concentrated $\mathrm{KOH}$ solution (3 molar solution) affects the porosity only slightly. A significant increase in porosity can be achieved by activation with 9 molar $\mathrm{KOH}$ solution. In all cases, the isotherms keep their type I shape indicating that exclusively new micropores have been created by the activation step.

Isotherms of activated carbons made from cellulose fibers are shown in Figure 6. Textural data of these materials are given in Table 4.

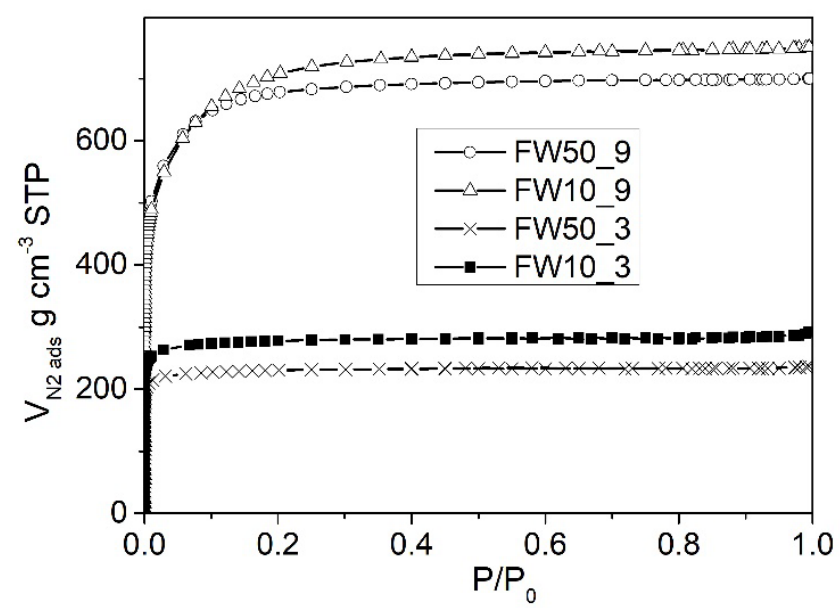

Figure 6. Nitrogen adsorption isotherms of selected carbon materials made from cellulose fibers.

Table 4. Textural data of samples shown in Figure 6.

\begin{tabular}{ccccc}
\hline & FW10_3 & FW10_9 & FW50_3 & FW50_9 \\
\hline$V_{\text {sp }}\left(\mathrm{cm}^{3} \mathrm{~g}^{-1}\right)$ & 0.44 & 1.16 & 0.36 & 1.08 \\
$S_{\text {BET }}\left(\mathrm{m}^{2} \mathrm{~g}^{-1}\right)$ & 928 & 2468 & 770 & 2324 \\
\hline
\end{tabular}

Here, nitrogen adsorption isotherms could only be obtained from the activated materials. Obviously, the non-activated carbons possess very narrow micropores which prevent the reaching of the adsorption equilibrium. In comparison with the carbons from microcrystalline cellulose, the activation of the fiber-derived carbons produces materials with larger porosity. The reason for this could be found in the differences of the morphology of the materials. As the fiber-derived carbons consist of a worm-like arrangement of carbon units the microcrystalline carbons are build-up by a network of manifoldly connected carbon units (Figure 1). So, more links between the carbon units have to be removed to create new porosity and the activated materials from $\mathrm{MC}$-carbon have a lower porosity than those from activated CF-carbons.

Furthermore, in difference to the above shown materials the pore system changes if higher concentrated $\mathrm{KOH}$ solution is used. The isotherms lost somewhat of their type I character indicating that part of the micropores has been widened due to the action of the activating agent. 


\subsection{Fracture Strength}

The fracture strength of the carbons from microcristalline cellulose is considerably higher than that of the fiber-derived materials (Figure 7).

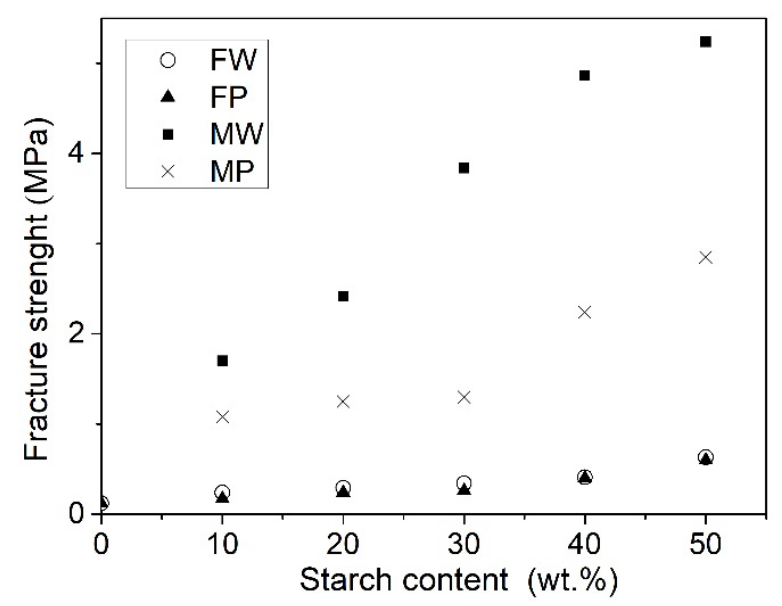

Figure 7. Dependence of the fracture strength from the composition of the carbon precursor.

Different facts could be responsible for these differences. First, there is a connection between the fracture strength and the total porosity (Figure 8). The total porosity is larger for the fiber-derived materials (Figure 4) and their fracture strength is considerably lower. As higher porosity is connected with lower matrix volume of the solid carbon skeleton, these materials are less stable against mechanical stress. However, the materials of the $\mathrm{M}$-series prepared with starch-rich precursor mixtures have-at nearly equal porosity - considerably higher fracture strength than the fiber-derived materials (Figure 8).

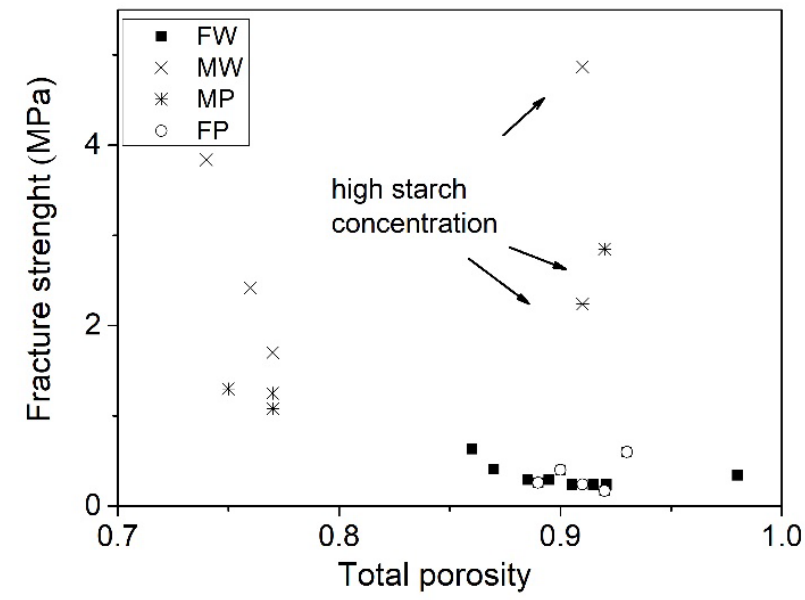

Figure 8. Dependence of the fracture strength from the total porosity of the carbon monoliths.

The differences in stability should be caused also by additional factors, such as the stability of the carbon skeleton. As mentioned above, the fiber-derived carbons of the F-series have another morphology than the carbons of the M-Series (Figure 1). These materials are build-up by an interconnected network of carbon units possessing numerous links between the carbon units. Obviously, that interconnected network causes not only the lower propensity to pore formation by the chemical activation, but also an enhanced mechanical stability. As a third factor, the chemical reactivity of the carbon species has to be considered. However, the carbon lost due to the activating process is nearly equal for all investigated materials. From that it can be concluded that the chemical reactivity of the carbon species against the activating agent is nearly the same for all materials. 
In addition, a strong correlation between the breaking strength and the starch content of the starting mixture could be found, especially for the carbons from microcrystalline cellulose. Furthermore, there are differences between the different types of starch. Monoliths prepared with wheat starch are significantly more stable than those prepared with potato starch. The reason for this is still far from being completely understood. Starch compounds are probably able to link cellulose fragments together. In this way, they contribute to the formation of a stable carbon framework. The observed differences between different kinds of starch are even more complicated to understand. To explain that behavior one has to focus on the properties of starch. The investigation of the reological properties during heating and cooling of starch suspensions show distinct differences between potato and wheat starch. Potato starch granules swell much more than wheat starch granules [22]. Wheat starch has compared with potato starch a larger number of entanglements between starch molecules which obviously reduces swelling and causes greater stiffness of their granules. Furthermore, in contrast to potato starch, the wheat starch contains residues of lipids which can also possibly explain the differences of the swelling capacity and stiffness, respectively [22]. So, differences in the mechanical properties exist already in the carbon precursor and can obviously be preserved during the carbonization process. Probably, the wheat starch fragments which exhibit greater stiffness will contribute to higher stability of subsequent formed carbon fragments.

\section{Conclusions}

The preparation method described here opens new ways to prepare porous carbon monoliths from bio-mass derived carbon precursors, namely cellulose and starch. These precursors can be transferred to a pasty-like prestage from which carbon monoliths with varied geometrical shape could be prepared. Patterns of relationship between features of the precursors and those of the corresponding carbons could be found. The fracture strength of the monoliths depends strongly from the nature of the cellulose and starch, respectively. Carbon monoliths obtained from microcrystalline cellulose are considerably more stable than those from cellulose fibers. Carbon from cellulose - wheat starch mixtures are more stable than those from cellulose - potato starch mixtures. Furthermore, there is a strong connection between the fracture strength and the starch content of the precursor mixture. The higher the starch content the higher the fracture strength of the carbons.

The differences in the fracture strength are reflected in the ability to be activated by $\mathrm{KOH}$. Fiber-derived carbons, which have only a low mechanic stability can very easily be activated by $\mathrm{KOH}$. In contrast, the microcrystalline cellulose derived carbons need higher concentrated solutions of the activating agent to obtain a remarkable increase in porosity.

The potential applications are manifold, such as electrode materials in applications for energy storage (batteries, capacitors), filtration devices or catalytic reactor systems. The investigations described here open new ways to develop novel modular carbon synthesis concepts for example by adding of heteratom-containing compounds (e.g., amino acids) or graphitization catalysts to the carbon precursor mixture. Both, heteroatoms like nitrogen and graphitic nanostructures, respectively, can modify the electronic properties of the carbon considerably. The challenge would consist of placing the materials between the triangle of the parameters' porosity, fracture strength and electronic properties in a defined way.

Supplementary Materials: The following are available online at http://www.mdpi.com/2311-5629/6/2/32/s1, Figure S1: X-ray diffraction measurements of cellulose, Figure S2: X-ray diffraction measurements of potato starch, Figure S3: Light-microscopic image of cellulose fibers (a) and microcrystalline cellulose (b), Figure S4: Light-microscopic image of potato starch (a) and wheat starch (b), Figure S5: Scheme of the carbon monolith preparation, Figure S6: Photograph of carbon monoliths made from microcrystalline cellulose (a) and cellulose fibers (b), Table S1: Overview of the used precursors, Table S2: Composition of the used carbon precursor mixtures-extended version, Table S3: Textural data of non-activated carbon monoliths made from microcrystalline cellulose and wheat starch, Table S4: Textural data of non-activated carbon monoliths made from microcrystalline cellulose and potato starch, Table S5: Textural data of activated carbon monoliths made from microcrystalline cellulose and potato starch, Table S6: Textural data of activated carbon monoliths made from microcrystalline 
cellulose and wheat starch, Table S7: Textural data of activated carbon monoliths made from cellulose fibers and potato starch, Table S8: Textural data of activated carbon monoliths made from cellulose fibers and wheat starch.

Author Contributions: Conceptualization, writing-original draft preparation, supervision, project administration, funding acquisition, O.K.; methodology, investigation, N.D. All authors have read and agreed to the published version of the manuscript.

Funding: This research was funded by the European Regional Development Fund (EFRE, Brandenburg, Proj. HL 23048413).

Acknowledgments: Thanks to the following laboratory of material testing (E. Hille) for allowing the experimental facilities to make fracture strength measurements and thanks to the laboratory of scanning electron microscopy (B. Glück) for allowing the experimental facilities to make SEM measurements. Thanks to S. Schickedanz, L. Wilk, M. Taubert, M. Erlitz and S. Utgenannt for support.

Conflicts of Interest: The authors declare no conflict of interest.

\section{References}

1. Kamm, B.; Gruber, P.; Kamm, M. Biorefineries-In dustrial Processes and Products, 1st ed.; Wiley-VCH: Weinheim, Germany, 2006.

2. Böhler, S.; Bartel, M.; Bohn, A.; Jacob, R.; Ganster, J.; Büsse, T.; Balko, J. Highly dense cellulose acetate specimens with superior mechanical properties produced by fused filament fabrication. Polymer 2020, 194, 122388. [CrossRef]

3. Auer, E.; Freund, A.; Pietsch, J.; Tacke, T. Carbons as supports for industrial precious metal catalysts. Appl. Catal. A 1998, 173, 259-271. [CrossRef]

4. Marsh, H.; Rodriguez-Reynoso, F. Activated Carbon, 1st ed.; Elsevier: Oxford, UK, 2006.

5. Serp, P.; Figueiredo, J.L. Carbon Materials for Catalysis, 1st ed.; Wiley\&Sons: Hoboken, NJ, USA, 2009.

6. Nishihara, H.; Kyotani, T. Templated nanocarbons for energy storage. Adv. Mater. 2012, 24, 4473-4498. [CrossRef] [PubMed]

7. Wang, J.; Kaskel, S. KOH activation of carbon-based materials for energy storage. J. Mater. Chem. 2012, 22, 23710-23725. [CrossRef]

8. Kyotani, T.; Ma, Z.; Tomita, A. Template synthesis of novel porous carbons using various types of zeolites. Carbon 2003, 41, 1451-1459. [CrossRef]

9. Ryoo, R.; Joo, S.H.; Jun, S. Synthesis of highly ordered carbon molecular sieves via template-mediated structural transformation. J. Phys. Chem. B 1999, 103, 7743-7746. [CrossRef]

10. Juhl, A.C.; Elverfeldt, C.-P.; Hoffmann, F.; Fröba, M. Porous carbon monoliths with pore sizes adjustable between $10 \mathrm{~nm}$ and $2 \mathrm{~mm}$ prepared by phase separation-New insights in the relation between synthesis composition and resulting structure. Microporous Mesoporous Mater. 2018, 255, 271-280. [CrossRef]

11. Adelhelm, P.; Hu, Y.-S.; Chuenchom, L.; Antonietti, M.; Smarsly, B.M.; Maier, J. Generation of Hierarchical Meso- and Macroporous Carbon from Mesophase Pitch by Spinodal Decomposition using Polymer Templates. Adv. Mater. 2007, 19, 14012-14017. [CrossRef]

12. Gutiérrez-Pardo, A.; Ramirez-Rico, J.; de Arellano-López, A.R.; Martinez-Fernández, J. Characterization of porous graphitic monoliths from pyrolyzed wood. J. Mater. Sci. 2014, 49, 7688-7696. [CrossRef]

13. Budarin, V.; Clark, J.H.; Hardy, J.J.E.; Luque, R.; Milkowski, K.; Tavener, S.J.; Wilson, A.J. Starbons: New Starch-Derived Mesoporous Carbonaceous Materials with Tunable Properties. Angew. Chem. Int. Ed. 2006, 45, 3782-3786. [CrossRef]

14. Shuo, Z.; Cheng-yang, W.; Ming-ming, C.; Zhi-qiang, S.; Na, L. Preparation of carbon spheres from potato starch and its stabilization mechanism. New Carbon Mater. 2010, 25, 438-443. [CrossRef]

15. Xue, Z.; Chen, P.; Yang, Q.; Lifang, H.; Mu, S.; Cheng, B. Effects of low-temperature carbonization temperature and time on morphology of carbon particles from maize starch. J. Mater. Sci. 2014, 49, 2180-2186. [CrossRef]

16. Keetels, C.J.A.M.; van Vliet, T.; Walstra, P. Gelation and retrogradation of concentrated starch systems: 1. Gelation. Food Hydrocoll. 1996, 10, 343-353. [CrossRef]

17. Nishiyama, Y.; Langan, P.; Chanzy, H. Crystal Structure and Hydrogen-Bonding System in Cellulose I $\beta$ from Synchrotron X-ray and Neutron Fiber Diffraction. J. Am. Chem. Soc. 2002, 124, 9074-9082. [CrossRef] [PubMed]

18. Taguchi, A.; Smatt, J.H.; Linden, M. Carbon monoliths possessing a hierarchical, fully interconnected porosity. Adv. Mater. 2003, 15, 1209-1211. [CrossRef] 
19. Lu, A.H.; Smatt, J.H.; Backlund, S.; Linden, M. Easy and flexible preparation of nanocasted carbon monoliths exhibiting a multimodal hierarchical porosity. Microporous Mesoporous Mater. 2004, 72, 59-65. [CrossRef]

20. Xia, Y.; Mokaya, R. Ordered mesoporous carbon monoliths: CVD nanocasting and hydrogen storage properties. J. Phys. Chem. C 2007, 111, 10035-10039. [CrossRef]

21. Günther, D.; Beckmann, J.; Schöneich, M.; Schmidt, P.; Klepel, O. Porous concrete as a template for the synthesis of porous carbon materials. Carbon 2012, 50, 3096-3098. [CrossRef]

22. Taubert, M.; Beckmann, J.; Lange, A.; Enke, D.; Klepel, O. Attempts to design porous carbon monoliths using porous concrete as a template. Microporous Mesoporous Mater. 2014, 197, 58-62. [CrossRef]

23. Klepel, O.; Danneberg, N.; Dräger, M.; Erlitz, M.; Taubert, M. Synthesis of Porous Carbon Monoliths Using Hard Templates. Materials 2016, 9, 214. [CrossRef]

24. Klepel, O.; Taubert, M. Attempts to design porous carbon monoliths using porous concrete as a template-Part II: Some aspects of the pore formation mechanism. Microporous Mesoporous Mater. 2019, 280, 243-247. [CrossRef]

25. Sing, K.S.W.; Everett, D.H.; Haul, R.A.W.; Moscou, L.; Pierotti, R.A.; Rouquerol, J.; Siemieniewska, T. Reporting Physisorption Data for Gas/Solid Systems with Special Reference to the Determination of Surface Area and Porosity. Pure Appl. Chem. 1985, 157, 603-619. [CrossRef]

(C) 2020 by the authors. Licensee MDPI, Basel, Switzerland. This article is an open access article distributed under the terms and conditions of the Creative Commons Attribution (CC BY) license (http://creativecommons.org/licenses/by/4.0/). 